\title{
Radiotherapy-induced decreases in substance $P$ levels may potentiate melanoma growth
}

\author{
AYLIN FIDAN KORCUM ${ }^{1}$, SALIH SANLIOGLU ${ }^{2}$, GAMZE AKSU $^{1}$, NINA TUNCEL $^{1}$ and NURAY ERIN ${ }^{3}$ \\ Departments of ${ }^{1}$ Radiation Oncology, ${ }^{2}$ Medical Biology and Genetics, ${ }^{3}$ Internal Medicine, \\ Akdeniz University, School of Medicine, Antalya 07070, Turkey
}

Received November 24, 2008; Accepted January 21, 2009

DOI: 10.3892/mmr_00000103

\begin{abstract}
Substance P, a member of the tachykinin family, is expressed in primary invasive malignant melanomas, metastatic melanomas, melanomas in situ, atypical naevi, and spindle and epithelioid cell naevi. The role of substance $\mathrm{P}$ in cancer development and progression is not clear. Radiotherapy, which is used extensively in the treatment of malignancies, alters substance P levels. It is, however, not known whether radiotherapy affects substance $P$ levels in melanomas or in the tumor microenvironment. Given the fact that melanomas express substance $\mathrm{P}$, possible radiation-induced changes in substance $\mathrm{P}$ content may underlie their radio-resistance. Hence, the aim of the present study was to determine the effects of radiotherapy on the growth of B16F10 melanomas as well as on the tumor and systemic expression of substance $\mathrm{P}$. In vivo exposure of tumor-bearing $\mathrm{C} 5 \mathrm{BL} / 6$ mice to ionizing radiation (45 Gy administered in three fractions) arrested tumor growth for three weeks and induced 3-fold increases in survival, as well as decreasing substance P levels in primary tumors and the surrounding skin. Although radiotherapy was applied locally $(1 \times 1 \mathrm{~cm})$ at the mid-flank region of the animal, it also induced systemic changes in the levels of substance P. Specifically, radiotherapy decreased substance P levels in skin distant from the radiation field as well as in the lungs and adrenals. In order to understand the significance of this effect, B16F10 cells and cells made from metastatic lesions (B16LNAD cells) were treated with substance P. Substance P inhibited the growth of B16F10 and B16LNAD cells and further potentiated the inhibitory effects of radiotherapy. These findings demonstrate for the first time that substance $\mathrm{P}$ inhibits melanoma growth, and that radiotherapy-induced decreases in substance $\mathrm{P}$ levels may underlie the radio-resistance of melanomas.
\end{abstract}

Correspondence to: Dr Nuray Erin, Department of Internal Medicine, Akdeniz University, School of Medicine, Antalya 07070, Turkey

E-mail: nerin@akdeniz.edu.tr; aylinf@hotmail.com

Key words: radiotherapy, substance P, melanoma, metastatic

\section{Introduction}

Cutaneous malignant melanoma is a rare but highly aggressive disease responsible for approximately $70 \%$ of skin cancerrelated mortalities. Once melanoma spreads to the lymph nodes, patient survival decreases markedly, despite new treatment modalities (1). Hence, there is an urgent need for novel therapies, which requires a better understanding of the mechanisms of the disease as well as of traditional treatments.

Substance P (SP), a member of the tachykinin family, is expressed by both neuronal and non-neuronal cells, and is involved in neurogenic inflammation, the sensation of pain, the regulation of immune response, and cancer progression. Specifically, SP induces cell proliferation by activating neurokinin 1 receptors in melanoma cells (2). It is expressed in primary invasive malignant melanomas, metastatic melanomas, melanomas in situ, atypical naevi, and spindle and epithelioid cell naevi (3). These findings suggest that the autocrine secretion of SP promotes the growth and metastases of melanoma. Conversely, we observed that the depletion of SP from sensory nerve endings increased breast cancer metastases $(4,5)$. Furthermore, treatment with SP decreased the growth of melanomas, small-cell lung cancer, colon cancer and prostate cancer (6-14). The role of SP during metastatic growth is therefore controversial, and requires further study.

Radiotherapy (RT) is used extensively in the treatment of many cancerous growths, such that over half of all cancer patients receive radiation therapy during the course of their treatment (15). Radiobiological studies have demonstrated that melanomas are formed by a heterogeneous group of cells, some of which are radiosensitive (16-19). The factors involved in the radiosensitivity of tumor cells are not completely known. Detailed studies performed by Overgaard (17) demonstrated that hypofractionated doses of RT are the most effective. This finding has been supported by other clinical studies (20-23).

RT has been shown to induce SP expression in breast cancer cell lines (24). It is not known whether RT affects SP levels in melanomas. Given the fact that melanomas express $\mathrm{SP}$, possible radiation-induced alterations in SP expression may be involved in its RT-resistance.

There have been a limited number of studies examining the effects of RT on B16F10 melanomas in-vivo. None of these studies examined the long term effects of high doses of radiation on tumor growth, metastases, and changes in SP 
levels. Hence, the present study had several goals: first, to determine the effects of RT on melanomas formed with $\mathrm{B} 16 \mathrm{~F} 10$ cells in C57BL/6 mice; second, to determine RTinduced changes in both tumor and systemic SP expression; and finally, to evaluate the effects of exogenously administered SP on the growth inhibitory effects of RT in B16F10 cells and their metastatic derivative line, B16LNAD.

\section{Materials and methods}

C57BL/6 mice (8-12 weeks old of both sexes) were used in the study. Animals were inbred at Akdeniz University, School of Medicine, Research Animal Facilities. All protocols were approved by the Animal Research Ethics Committee of Akdeniz University. The SP EIA Kit was obtained from Cayman Chemicals (cat no. 583751).

B16F10 melanoma cells were grown in DMEM-F12 medium supplemented with non-essential amino acids, sodium pyruvate and $5 \%$ fetal bovine serum (FBS). B16F10 cells $\left(10^{6}\right)$ were injected subcutaneously into the left mid-flank region of the C57BL/6 mice under ether anesthesia.

Each mouse was irradiated in the Co-60 teletherapy unit at a $100-\mathrm{cm}$ distance under ketamin/xylazine anesthesia $48 \mathrm{~h}$ after the inoculation of the cells. The collimated irradiation field was $1.5 \mathrm{~cm}^{2}$ at the skin of the mid-flank region using a fabricated lead alloy block. The dose rate at irradiation was $\sim 65 \mathrm{cGy} / \mathrm{min}$. The prescribed dose of $45 \mathrm{~Gy}$ was delivered at three fractions of $15 \mathrm{~Gy}$ two days apart. Control animals were only treated with ketamin/xylazine to rule out possible effects of anesthesia on tumor growth.

Initial studies were performed using 1000-5000 cells/well seeded in 96-well plates for screening the effects of ionizing radiation and of SP treatment on cell growth in vitro. In addition to B16F10 cells, B16LNAD cells obtained from several abdominal lymph node metastases and a sample of adrenal metastasis found in one RT-treated mouse (LNAD, lymph node and adrenal metastasis) were also used. Cells were treated with SP $(10-0.001 \mu \mathrm{M}) 36 \mathrm{~h}$ after plating and were irradiated with a single dose of ionizing radiation $5 \mathrm{~h}$ after SP treatment. Cell growth was determined $48 \mathrm{~h}, 72 \mathrm{~h}$ or 7 days after irradiation. Each cell plate (2-cm thick) was irradiated in the Co-60 teletherapy unit at a distance of $100 \mathrm{~cm}$. In order to achieve a homogeneous dose $(+\% 2.5)$ at the cell plate, the plate was embedded on water equivalent bolus material and $0.5-\mathrm{cm}$ thick bolus material was placed on the cover of this as well. The prescribed dose was 20 or 45 Gy at $1.5 \mathrm{~cm}$ (in the middle of the plate), and the dose rate at irradiation was $\sim 145 \mathrm{cGy} / \mathrm{min}$. Cell proliferation was evaluated using the tetrazolium compound 3-(4,5-dimethylthiazol-2yl)-5-(3-carboxymethoxyphenyl)-2-(4-sulphophenyl)-2Htetrazolium, inner salt (MTS) according to the manufacturer's instructions (Cell Titer 96 Aqueous One Solution Cell Proliferation Assay; Promega Corp., Madison, WI, USA). Formation of formasan determined at OD 490 was compared between the groups.

After an initial screening with the MTS cell proliferation assay, two SP concentrations were chosen, and the total cell and living cell numbers were determined using the trypan blue exclusion test. For this purpose, cells were seeded on 6or 12 -well plates $(100,000$ or 50,000 cells/well, respectively) and treated with vehicle or SP $36 \mathrm{~h}$ after plating. Ionizing radiation $(45 \mathrm{~Gy})$ was applied $5 \mathrm{~h}$ after treatment. Experiments were terminated $72 \mathrm{~h}$ after the RT. Each experiment was repeated three to five times.

For SP measurements, cells were seeded in 6-well plates $(200,000$ cells/well) and irradiated in serum-free medium. Conditioned medium was collected $48 \mathrm{~h}$ after irradiation, and SP was extracted using the Oasis Extraction Column (Waters Corp., MA, USA). SP extractions from tissues were performed as previously described without column extraction (25), with the following exception: a two-step extraction was performed for lung and skin samples. Briefly, samples were incubated in $2 \%$ acetic acid at $95^{\circ} \mathrm{C}$ for 15 min, supernatants were removed (first extraction) and the pellets were incubated in $2 \%$ acetic acid at $95^{\circ} \mathrm{C}$ for $45 \mathrm{~min}$ for the second extraction. Supernatants were dried in a speed-vacuum and re-suspended in sample buffer provided in the SP EIA Kit. Single extraction for $60 \mathrm{~min}$ was used for adrenal and tumor tissue.

Statistical analysis. Data were evaluated using the Student's t-test. A P-value $<0.05$ was considered to be statistically significant.

\section{Results}

Radiotherapy markedly suppresses tumor growth and increases survival. Animals received 3 x 15 Gy ionizing radiation $48 \mathrm{~h}$ apart locally. The first dose was applied $48 \mathrm{~h}$ after the injection of the B16F10 cells. As shown in Fig. 1A, tumor growth in untreated animals (control) was very rapid, reaching $13 \mathrm{~mm}$ in diameter within 2 weeks $(n=10)$. On the other hand, in animals treated with RT, the growth of primary tumors was arrested for 3 weeks $(n=5)$. Similarly, the sizes of the primary tumors did not reach control levels, even 2 months after RT. This demonstrates that tumors formed by B16F10 cells were radiosensitive in vivo.

Survival was determined using the time point when animals were heavily morbid, such that their movements were markedly slowed down or that they experienced respiratory distress. We previously observed that once the mobility of the animals was markedly impaired, they died within a day. As shown in Fig. 1B, the lifespan of the RT-treated animals was increased 3- to 4-fold, reaching 67 days in one animal. Treated animals became heavily morbid due to multiple skin and lymph node metastases. Metastatic nodules were fast growing and, once metastatic lesions appeared, the animals became morbid within a week. Multiple skin metastases were observed in all the animals, and three animals had macroscopic inguinal and axial lymph node metastases of 3-5 mm in diameter each. Two animals also had metastases on the abdominal lymph nodes, and one had macroscopic adrenal and lung metastases.

Radiotherapy alters SP levels locally and systemically. SP levels were determined in primary tumors, in skin adjacent to the primary tumors, and in the adrenals and lungs. Skin samples distant from primary and metastatic tumors were also examined. RT significantly decreased SP levels in primary tumors 50-60 days after the final dose of radiation (Fig. 2A).

Skin SP originates from neuronal and non-neuronal cells. We previously demonstrated that neuronal SP was extracted 
A

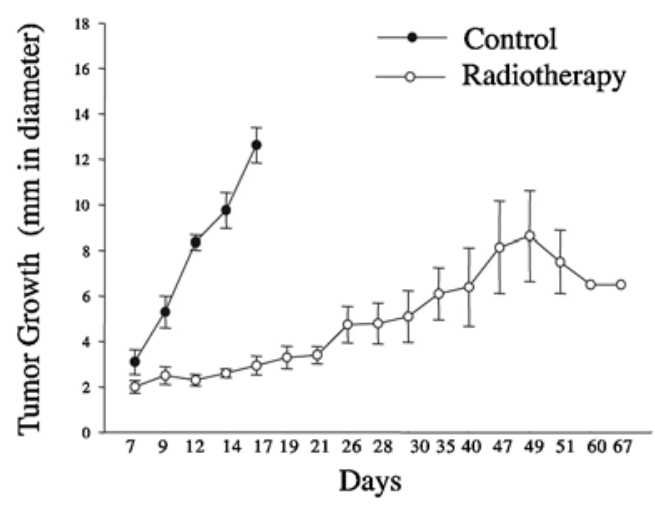

B

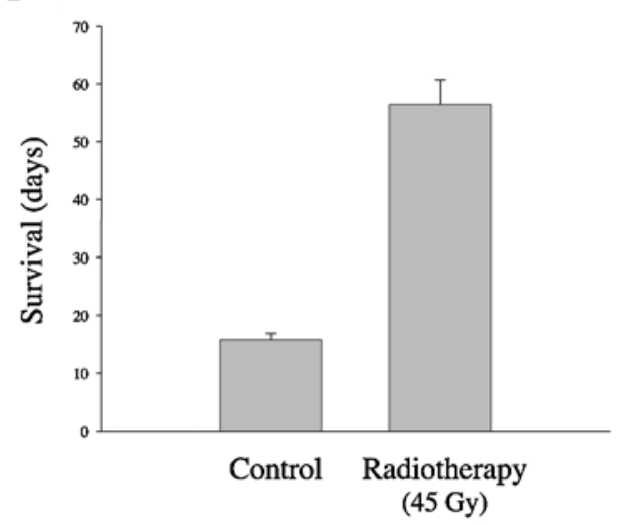

Figure 1. The effects of radiotherapy on tumor growth. Animals received 3 x 15 Gy ionizing radiation 2 days after the injection of B16F10 cells. (A) Changes in tumor growth after radiotherapy. (B) Effects of radiotherapy on survival.

A

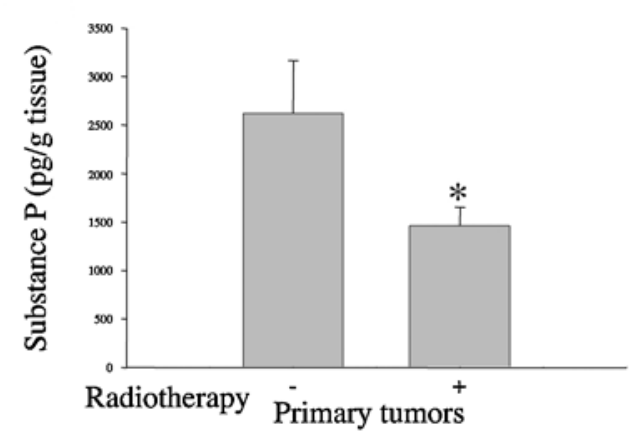

$\mathrm{C}$

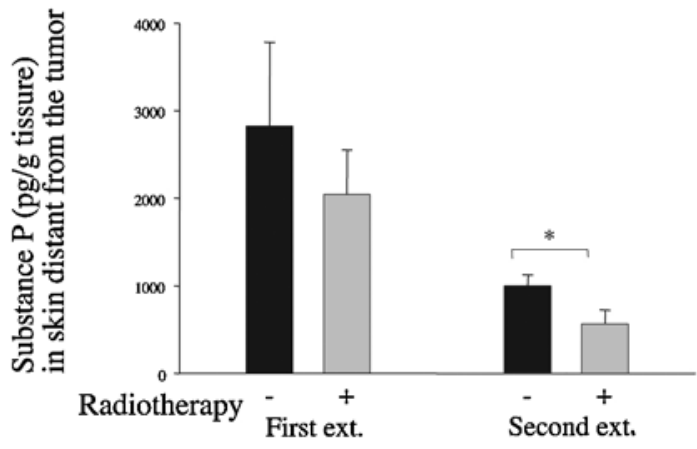

within the initial extraction of 5-15 min, while the second extraction included non-neuronal SP (26). Hence, a two-step acetic acid extraction was used. Unexpectedly, tumor growth alone decreased SP levels in skin samples distant to the primary tumor. The reduction was evident in first as well as second extractions. RT further decreased SP levels of unirradiated skin in the second extraction (Fig. 2B), demonstrating that non-neuronal cells of the skin, such as fibroblasts and keratinocytes, were also affected.

The effect of RT on SP levels in the skin surrounding the primary tumor was similar to its effects on tumor cells and on
B

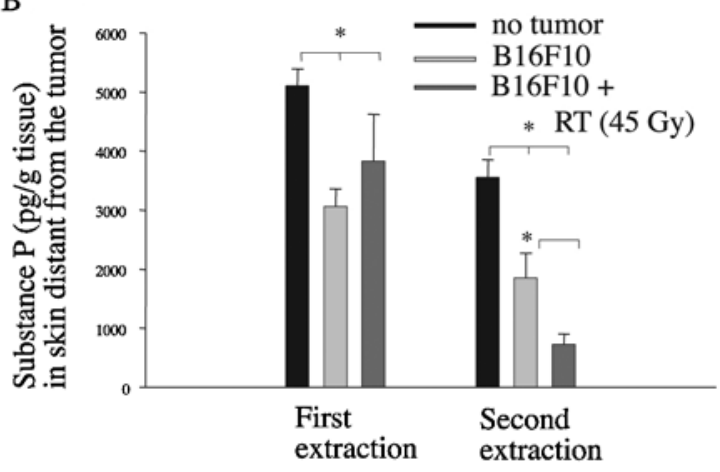

Figure 2. The effects of radiotherapy on tissue substance P levels. Substance $P$ levels were determined using two-step acetic acid extraction as described in Materials and methods. (A) Changes in substance P levels in primary tumors obtained from controls and animals treated with ionizing radiation. (B) Changes in substance $\mathrm{P}$ levels in skin distant from the tumor. Tissues were taken from control animals (no tumor) and from the melanoma cells of untreated tumor-bearing animals and radiotherapy-treated tumor-bearing animals. (C) Substance P levels in skin adjacent to the tumors as well as in the lungs and adrenals, respectively. ${ }^{*} \mathrm{p}<0.05$, significantly different as compared to the control group; Student's t-test.

distant skin. The amount of SP obtained in the second extraction decreased significantly in skin samples adjacent to the primary tumor of irradiated animals. SP recovered in the first extraction was also slightly decreased (Fig. 2C).

Although ionizing radiation was applied locally to the mid-flank region, SP levels were also altered in relatively distant organs. Specifically, RT decreased total SP levels of the lung and the adrenals compared to the tumor-bearing untreated animals. In contrast to the skin, the presence of the tumor did not alter lung and adrenal SP levels (data not shown). 

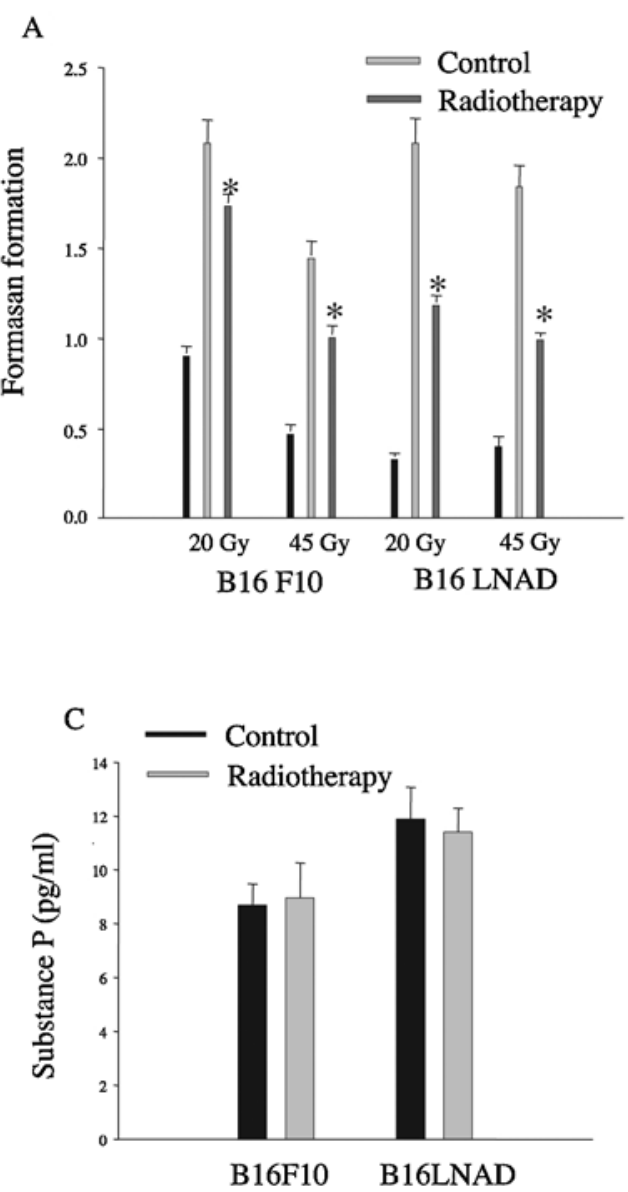

In-vitro effects of radiotherapy on cell growth and SP levels. We examined the acute effects of RT on cell growth and SP levels in B16F10 cells and in the B16LNAD cell line from metastatic lesions. Cells (1000-5000 cells/well in a 96-well plate) were plated, medium was exchanged with serum-free medium, and RT was applied $36 \mathrm{~h}$ after plating. Cell growth was determined $48 \mathrm{~h}$ after a single dose of ionizing radiation (45 or 20 Gy) (Fig. 3A). Although RT almost completely arrested cell growth in vivo, at both doses it only slowed down the growth of B16F10 cells by $30 \%$.

Interestingly, B16LNAD cells were more sensitive to ionizing radiation. This may be due to the higher rate of proliferation of B16LNAD cells observed here (27). Time 0 levels in Fig. 3A register the formation of formasan, an indicator of cell number, just before RT. The cell number $48 \mathrm{~h}$ after the initial readings of untreated cells (control) demonstrates that B16LNAD cells proliferate much faster than B16F10 cells. Specifically, after $48 \mathrm{~h}$, the number of B16F10 cells was increased 2.6-fold, whereas the number of B16LNAD cells was increased 5.2-fold. The cell growth rate of B16F10 cells after RT was also determined 1 week after irradiation. There was no difference in the extent of growth inhibition induced by RT (Fig. 3B).

Changes in SP levels following RT were also examined. Cells were plated $(200,000$ cells/well in 6-well plates) $36 \mathrm{~h}$ before RT. Medium was replaced with serum-free medium just before RT. SP levels were determined in conditioned media that were removed $48 \mathrm{~h}$ after RT. As shown in Fig. 3C, RT did not alter the amount of SP released from B16F10 or
B

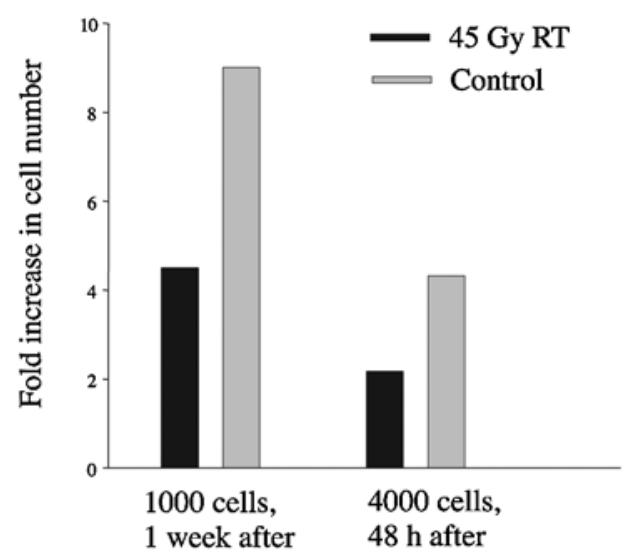

Figure 3. The effect of radiotherapy on cell growth and SP levels in vitro. (A) B16F10 and B16LNAD cells (metastatic derivative of B16F10 cells) were treated with a single dose of 20 or 45 Gy of ionizing radiation, and cell growth was determined after $48 \mathrm{~h}$ using MTS solution. Time 0 demonstrates cell numbers before radiotherapy. (B) Time-dependent changes in the growth of B16F10 cells after RT. (C) Changes in substance P levels in medium $48 \mathrm{~h}$ after radiotherapy. ${ }^{*} \mathrm{p}<0.05$, significantly different as compared to the control group; Student's t-test.

B16LNAD cells. Similarly, SP levels in cells made from metastatic lesions (B16LNAD) did not differ from levels in the parental cell line (B16F10).

Substance P treatment inhibits the growth of B16F10 cells and enhances the growth inhibitory effects of $R T$. As described above, 50-60 days after RT, SP levels decreased in both the tumor and surrounding tissue. The significance of this effect on tumor progression was not known. To clarify the role of SP in tumor growth, B16F10 cells plated on 12-well plates were treated with SP (1 and $0.1 \mu \mathrm{M}$ in serum-free medium as well as medium supplemented with $1 \%$ FBS, with four repeats of each treatment). Live cells as well as the total cell number were determined $72 \mathrm{~h}$ after SP treatment using the trypan blue exclusion test. In a second set of experiments, SP treatment was combined with RT (45 Gy).

As shown in Fig. 4, SP dose-dependently decreased the number of live cells in the control group (not irradiated) and increased the cytotoxic effects of RT. However, the total number of cells was not affected by SP treatment, which indicates that SP did not inhibit cell proliferation but rather induced cell death. Specifically, cell death was evident, with an abundance of condensed seemingly apoptotice cells and cell fragments in the control group treated with $1 \mu \mathrm{M} \mathrm{SP}$ (Fig. 4A), as well as in the RT group treated with 0.1 and $1 \mu \mathrm{M} \mathrm{SP}$. Surprisingly, microscopically visible dead cells were very few in the group which received RT only, indicating that RTinduced cell death is a late event that is not evident by $72 \mathrm{~h}$ (Fig. 4A). The growth inhibitory and cytotoxic effects of SP 
A

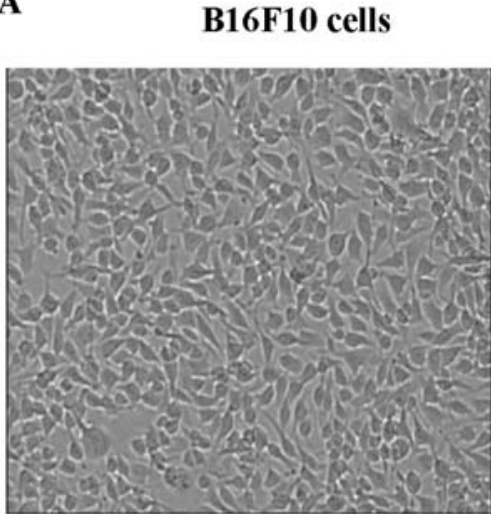

Vehicle

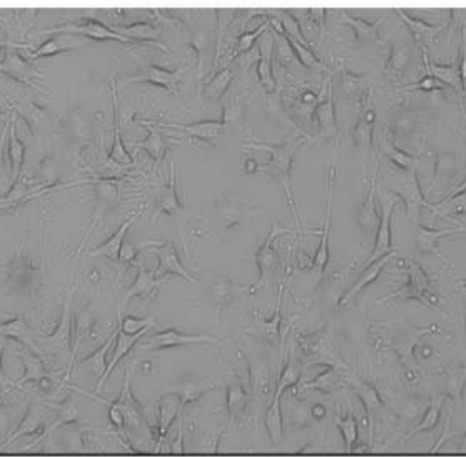

Vehicle

\section{CONTROL}

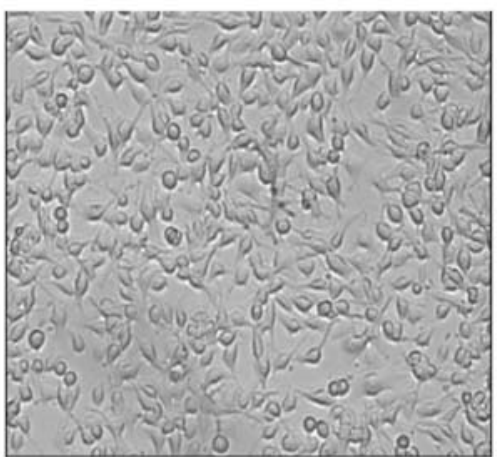

$0.1 \mu \mathrm{M}$ Substance P

\section{RT-45 Gy}

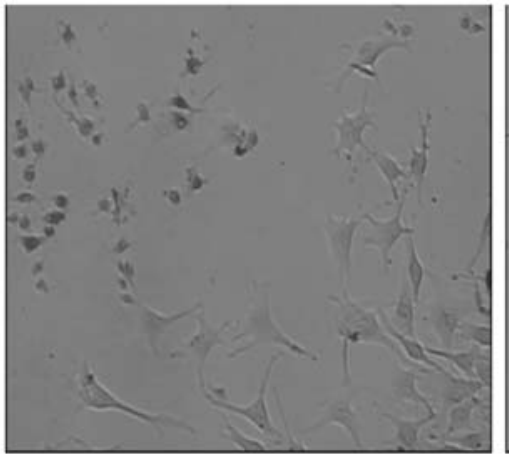

$0.1 \mu \mathrm{M}$ Substance $\mathrm{P}$

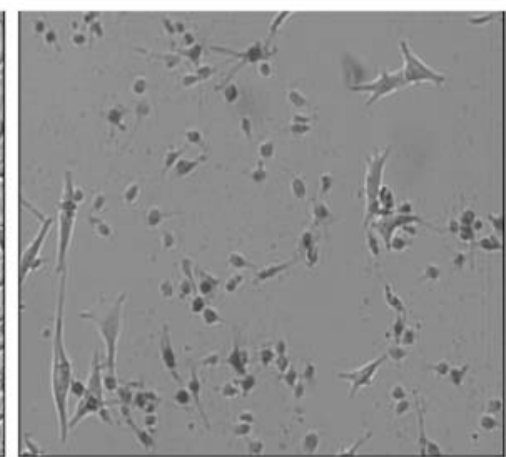

$1 \mu \mathrm{M}$ Substance P

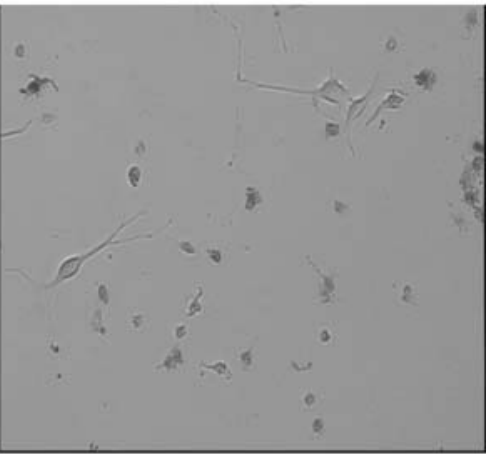

$1 \mu \mathrm{M}$ Substance P
B

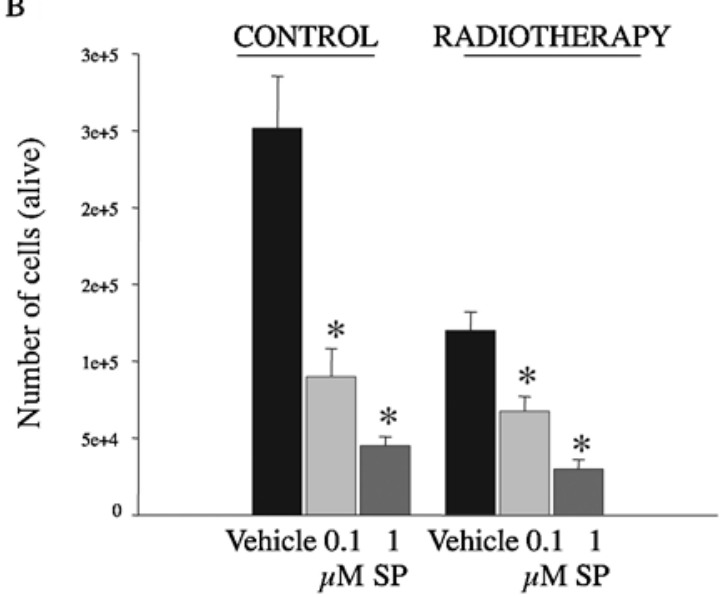

C

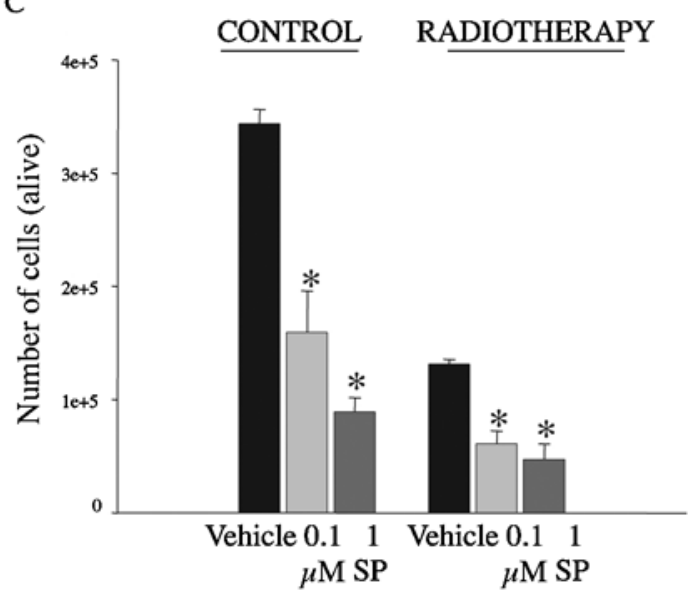

Figure 4. Effects of substance P treatment on cell growth. B16F10 cells were seeded in 12-well plates (50,000 cells/well) and the number of live cells was determined by the trypan blue exclusion test. (A) Appearance of the cells under a contrast phase microscope. B16F10 cells were treated in serum-free medium. (B and C) Changes in the number of live cells following substance P treatment $(0.1$ and $1 \mu \mathrm{M})$ in the absence or presence of $1 \%$ FBS, respectively. ${ }^{*}$ p $<0.05$, significantly different as compared to the control group; Student's t-test.

were evident in serum-free conditions as well as in the presence of $1 \%$ FBS (panel 4C). These experiments were repeated 3-4 times. The percent decrease in cell survival was calculated for each experiment, and the average of 3-4 experiments is shown in Table I. The results demonstrate that SP inhibits the growth of melanoma and potentiates the antitumor effects of RT.
SP inhibits the growth of B16LNAD cells and enhances the growth inhibitory effects of $R T$. The experiments described above were repeated using B16LNAD cells in order to determine the effects of SP on metastatic cells. The results were similar, with SP proving equally effective in decreasing cell survival. This effect was dose-dependent and was evident in the presence and absence of FBS (Fig. 5). Fig. 5A shows the 
A

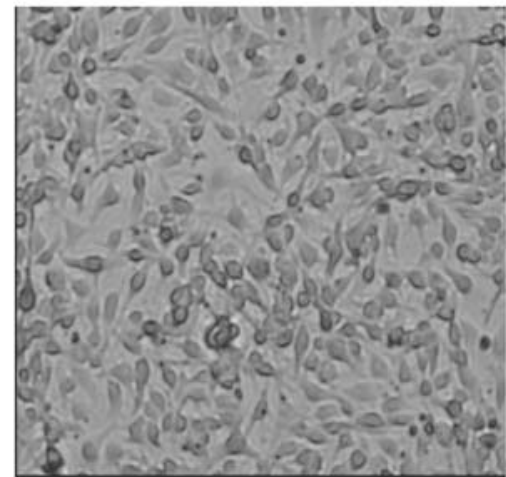

Vehicle

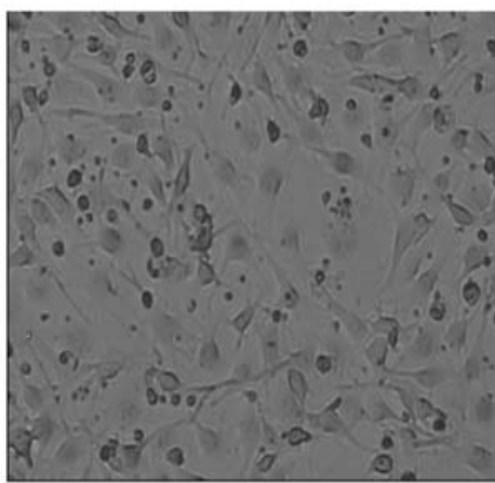

Vehicle

B16LNAD cells

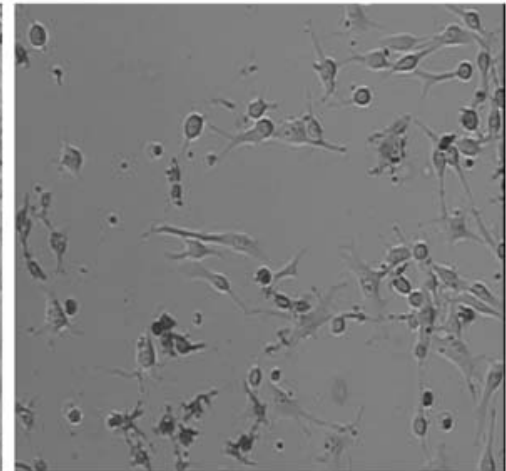

$0.1 \mu \mathrm{M}$ Substance P

RT-45 Gy

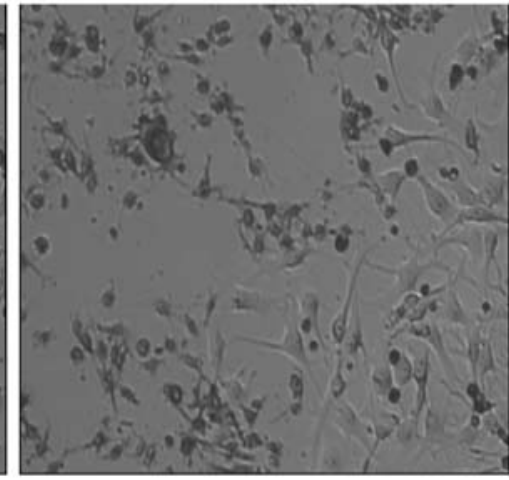

$0.1 \mu \mathrm{M}$ Substance P

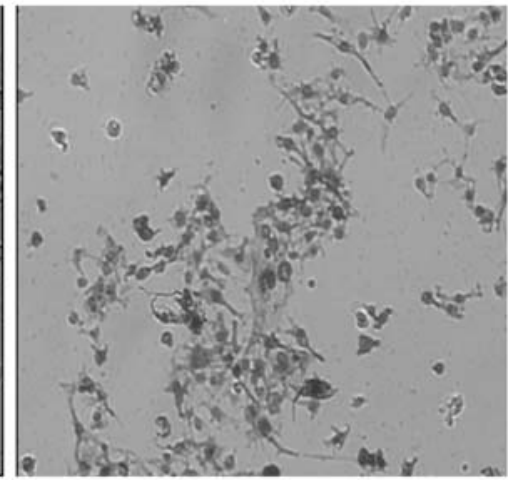

$1 \mu \mathrm{M}$ Substance $\mathrm{P}$

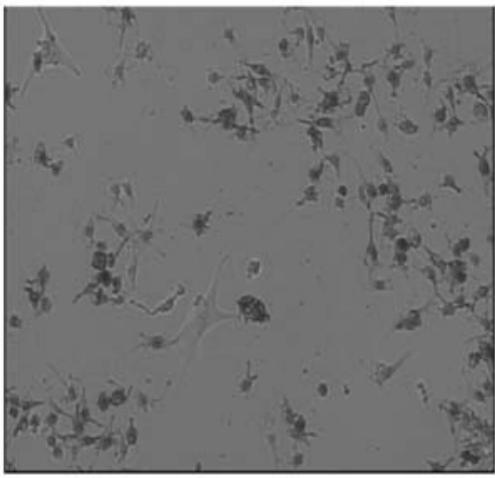

$1 \mu \mathrm{M}$ Substance P
B

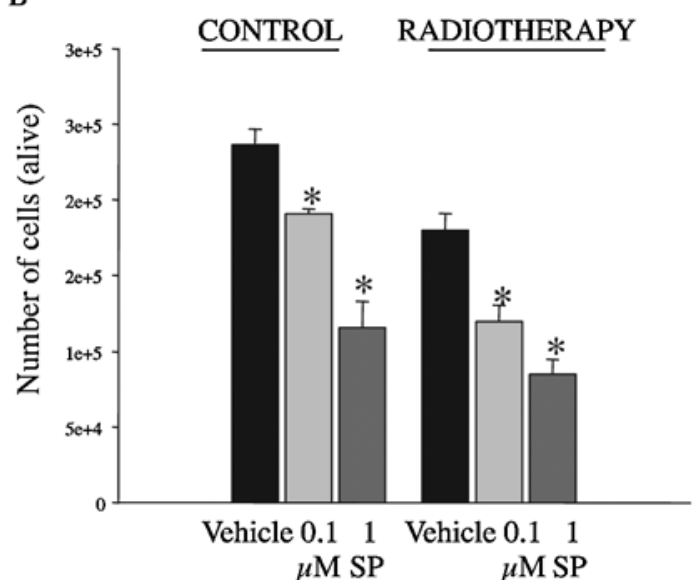

C

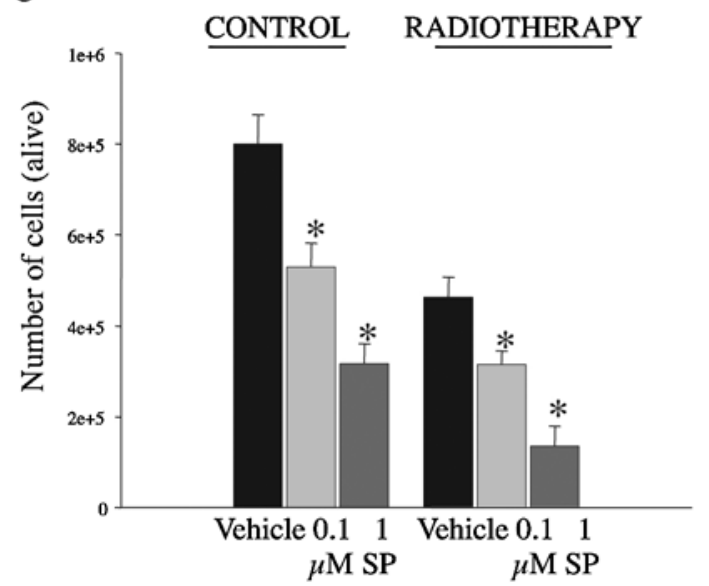

Figure 5. Effects of substance P treatment on cell growth. B16LNAD cells were seeded in 12-well plates (50,000 cells/well) and the number of live cells was determined by the trypan blue exclusion test. (A) Appearance of the cells under a contrast phase microscope. B16LNAD cells were treated in serum-free medium. (B and $\mathrm{C}$ ) Changes in the number of live cells following substance $\mathrm{P}$ treatment $(0.1$ and $1 \mu \mathrm{M})$ in the absence or presence of $1 \%$ FBS, respectively. ${ }^{*} \mathrm{p}<0.05$, significantly different as compared to the control group; Student's t-test.

appearance of cells under a contrast phase microscope. RT alone seemed to induce more cell death in B16LNAD cells than in B16F10 cells, as condensed cells and cell remnants were observed more frequently (Fig. 5A). These experiments were repeated 3-4 times, and representative results are shown in Fig. 5B and C. The cumulative results of the 3-4 experiments are shown in Table I.

\section{Discussion}

Our results demonstrate for the first time that radiotherapy decreases SP levels in melanoma as well as in local and distant tissues, which in turn may antagonize the therapeutic effects of RT and induce tumor progression. We found that in-vitro SP treatment suppressed the growth of B16F10 melanoma 
Table I. Cummulative results of SP cytotoxicity in B16F10 and BLNAD cells. ${ }^{\mathrm{a}}$

\begin{tabular}{|c|c|c|c|c|c|}
\hline & & \multicolumn{2}{|c|}{$\begin{array}{c}\text { Control } \\
\% \text { decrease in cell survival }\end{array}$} & \multicolumn{2}{|c|}{$\begin{array}{c}\text { Radiotherapy } \\
\% \text { decrease in cell survival }\end{array}$} \\
\hline & & $0.1 \mu \mathrm{M} \mathrm{SP}$ & $1 \mu \mathrm{M} \mathrm{SP}$ & $0.1 \mu \mathrm{M} \mathrm{SP}$ & $1 \mu \mathrm{M} \mathrm{SP}$ \\
\hline BLNAD & $\begin{array}{l}\text { Serum-free } \\
1 \% \text { serum }\end{array}$ & $\begin{array}{l}35.86 \pm 2.095 \\
22.07 \pm 6.376\end{array}$ & $\begin{array}{r}56.4 \pm 12.29 \\
40.81 \pm 9.934\end{array}$ & $\begin{array}{l}27.6 \pm 15.6 \\
30.8 \pm 13.1\end{array}$ & $\begin{array}{l}57.7 \pm 13.1 \\
70.5 \pm 5.52\end{array}$ \\
\hline B16F10 & $\begin{array}{l}\text { Serum-free } \\
1 \% \text { serum }\end{array}$ & $\begin{array}{l}41.76 \pm 18.33 \\
36.21 \pm 18.13\end{array}$ & $\begin{array}{l}61.22 \pm 10.46 \\
51.63 \pm 11.56\end{array}$ & $\begin{array}{l}59.0 \pm 20.7 \\
38.5 \pm 10.3\end{array}$ & $\begin{array}{l}62.6 \pm 6.57 \\
69.3 \pm 5.91\end{array}$ \\
\hline
\end{tabular}

aEach experiment was repeated 3-5 times, and \% decrease in cell survival was determined. The formula used for the control group was: 100 - (number of live cells in the treated control group/number of live cells in untreated control group) x 100. The formula used for RT was: 100 - (number of live cells in treated RT-receiving group/number of live cells in untreated RT-receiving group) x 100.

cells and their metastatic derivative, B16LNAD. Furthermore, SP potentiates the anti-tumoral effects of RT.

These findings may seem surprising at first glance, given that SP is a mitogenic peptide known to induce angiogenesis and tumor cell proliferation (2). Studies indicate, however, that the effect of SP is dependent on the tumor model in which it is examined. While, in some models, SP has been found to stimulate tumor growth, other studies have documented the opposite effect (6-14,28-31). For example, it has been demonstrated that pre-treatment of mice with SP protects against melanoma growth by inducing anti-tumor immunity. Additionally, silencing of the SP gene has been implicated in colon carcinogenesis (6,32). Flageole et al reported that SP increases the cytotoxic immune response to colorectal cancer cells (12). SP has also been shown to supress the motility of cancer cells, decreasing invasiveness in prostate cancer (14). Lastly, aerosolized SP has been shown to protect against cigaretteinduced lung damage and tumor development (7). Our results further confirm these findings and demonstrate the antitumoral effects of SP against melanoma. Furthermore, we show for the first time that SP increases sensitivity to RT.

B16F10 melanomas seem to be resistant to low-to-moderate doses of RT. Tumor growth was not significantly inhibited in mice treated with a single dose of 10 Gy 7 days after the inoculation of B16F10 cells (33). Recently, Jin et al demonstrated that 5 Gy x 3 radiation suppresses the growth of B16F10 melanomas by approximately $50 \%$ on day 16 (34). Since moderate doses of RT did not completely suppress the growth of B16F10 melanomas, we used relatively high doses of radiation. Specifically, three fractions of $15 \mathrm{~Gy}$, which were found to be very effective in patients with uveal melanoma, were administered $48 \mathrm{~h}$ after the inoculation of the cells (35).

Our findings demonstrate that, besides having local effects, high-dose radiation has systemic side effects, such as altering the neuropeptide content of the skin and viseral organs. We observed that melanoma decreases distal skin, lung and adrenal SP levels. Similarly, Höckerfelt et al reported that nerve fibers containing SP and vasoactive intestinal peptide in colon mucosa decreased 5-6 weeks after abdominal RT, demostrating that RT decreases the survival of peptidergic sensory neurons (36). Sensory neurons are involved in wound healing, and the loss of their activity may lead to the late tissue damage observed following RT. Here, we also showed that SP has anti-tumoral effects, and that RTinduced loss of SP may potentiate tumor growth $(37,38)$.

A two-step acetic acid extraction was used to differentiate changes in neuronal and non-neuronal SP by a previously verified method (26). Surprisingly, we observed that nonneuronal SP decreased more than neuronal SP following RT. At present, we do not know the reasons for these differential effects, but they may be due to the partial regeneration of sensory fibers. Similar findings have been previously reported. For example, Forsgren et al found decreased levels of SP in the parenchyma, but not in ganglionic neuronal cells, 6 months after irradiation (39). It was also found that large dense-cored vesicles of sensory neurons, which store neuropeptides, were not affected by 45 Gy radiation (40).

In conclusion, substance $\mathrm{P}$ exhibited anti-tumoral effects against melanoma and potentiated the cytotoxic effects of radiotherapy. Further studies are needed to elucidate the mechanisms of the tumor suppressive effects of substance $\mathrm{P}$, and to determine its potential as a tumor suppressor in other malignancies.

\section{Acknowledgements}

This study was supported by the Akdeniz University Scientific Research Projects Unit, Marie Curie Actions Project no. MIRG-CT-2005-029097, and The Young Scientists Award Programme (GEBIP) of the Turkish Academy of Sciences.

\section{References}

1. Balch CM, Soong SJ, Gershenwald JE, et al: Prognostic factors analysis of 17,600 melanoma patients: validation of the American Joint Committee on Cancer melanoma staging system. J Clin Oncol 19: 3622-3634, 2001.

2. Esteban F, Muñoz M, González-Moles MA and Rosso M: A role for substance $\mathrm{P}$ in cancer promotion and progression: a mechanism to counteract intracellular death signals following oncogene activation or DNA damage. Cancer Metastasis Rev 25: 137-145, 2006.

3. Khare VK, Albino AP and Reed JA: The neuropeptide/mast cell secretagogue substance $\mathrm{P}$ is expressed in cutaneous melanocytic lesions. J Cutan Pathol 25: 2-10, 1998.

4. Erin N, Boyer PJ, Bonneau RH, Clawson GA and Welch DR: Capsaicin-mediated denervation of sensory neurons promotes mammary tumor metastasis to lung and heart. Anticancer Res 24: 1003-1009, 2004 
5. Erin N, Zhao W, Bylander J, Chase G and Clawson G: Capsaicininduced inactivation of sensory neurons promotes a more aggressive gene expression phenotype in breast cancer cells. Breast Cancer Res Treat 99: 351-364, 2006.

6. Manske JM and Hanson SE: Substance-P-mediated immunomodulation of tumor growth in a murine model. Neuroimmunomodulation 12: 201-210, 2005.

7. Harris DT and Witten M: Aerosolized substance P protects against cigarette-induced lung damage and tumor development. Cell Mol Biol 49: 151-157, 2003.

8. MacKinnon A and Sethi T: [D - Arg6, D-Trp7,9,NmePhe8]substance P (6-11) activates JNK and induces apoptosis in small cell lung cancer cells via an oxidant-dependent mechanism. Methods Mol Med 74: 299-307, 2003.

9. Seckl MJ, Higgins T, Widmer F and Rozengurt E: [D - Arg1,DTrp5,7,9,Leu11] substance P: A novel potent inhibitor of signal transduction and growth in vitro and in vivo in small cell lung cancer cells. Cancer Res 57: 51-54, 1997.

10. Orosz A, Schrett J, Nagy J, Bartha L, Schon I and Nyeki O: New short-chain analogs of a substance-P antagonist inhibit proliferation of human small-cell lung-cancer cells in vitro and in vivo. Int J Cancer 60: 82-87, 1995.

11. Nyeki O, Rill A, Schon I, Orosz A, Schrett J, Bartha L and Nagy J: Synthesis of peptide and pseudopeptide amides inhibiting the proliferation of small cell and epithelial types of lung carcinoma cells. J Pept Sci 4: 486-495, 1998.

12. Flageole H, Senterman M and Trudel JL: Substance P increases in vitro lymphokine-activated-killer (LAK) cell cytotoxicity against fresh colorectal cancer cells. J Surg Res 53: 445-449, 1992.

13. Ogasawara M, Murata J, Ayukawa K and Saimi I: Differential effect of intestinal neuropeptides on invasion and migration of colon carcinoma cells in vitro. Cancer Lett 116: 111-116, 1997.

14. Nagakawa O, Ogasawara M, Fujii H, Murakami K, Murata J, Fuse $\mathrm{H}$ and Saiki I: Effect of prostatic neuropeptides on invasion and migration of PC-3 prostate cancer cells. Cancer Lett 133: 27-33, 1998

15. Owen JB, Coia LR and Hanks GE: Recent patterns of growth in radiation therapy facilities in the United States: a pattern of care study report. Int J Radiat Oncol Biol Phys 24: 983-986, 1992.

16. Rofstad EK: Radiation biology of malignant melanoma. Acta Radiol Oncol 25: 1-10, 1986.

17. Overgaard J: The role of radiotherapy in recurrent and metastatic malignant melanoma: a clinical radiobiological study. Int $J$ Radiat Oncol Biol Phys 12: 867-872, 1986.

18. Rofstad EK: Influence of cellular radiation sensitivity on local tumor control of human melanoma xenografts given fractionated radiation treatment. Cancer Res 51: 4609-4612, 1991.

19. Rofstad EK: Radiation sensitivity in vitro of primary tumors and metastatic lesions of malignant melanoma. Cancer Res 52: 4453-4457, 1992

20. Dvorak E, Haas RE and Liebner EJ: Contribution of radiotherapy to the management of malignant melanoma. A ten year experience at the University of Illinois Hospital in Chicago. Neoplasma 40: 387-399, 1993.

21. Ang KK, Peters LJ, Weber RS, Morrison WH, Frankenthaler RA, Garden AS, Goepfert H, Ha CS and Byers RM: Postoperative radiotherapy for cutaneous melanoma of the head and neck region. Int J Radiat Oncol Biol Phys 30: 795-798, 1994

22. Stevens G, Thompson JF, Firth I, O'Brien CJ, McCarthy WH and Quinn MJ: Locally advanced melanoma: results of postoperative hypofractionated radiation therapy. Cancer 88: 88-94, 2000.

23. Chang DT, Amdur RJ, Morris CG and Mendenhall WM: Adjuvant radiotherapy for cutaneous melanoma: comparing hypofractionation to conventional fractionation. Int J Radiat Oncol Biol Phys 66: 1051-1055, 2006.
24. Aalto Y, Forsgren S, Kjörell U, Bergh J, Franzén L and Henriksson R: Enhanced expression of neuropeptides in human breast cancer cell lines following irradiation. Peptides 19: 231-239, 1998.

25. Erin $\mathrm{N}$ and Clawson GA: Parameters affecting substance $P$ measurement in heart, lung, and skin. Biotechniques 37: 232, 234, 2004

26. Erin N and Ulusoy O: Differentiation of neuronal from nonneuronal Substance P. Regul Pept 152: 108-113, 2009.

27. Sinclair WK: Cyclic x-ray responses in mammalian cells in vitro. Radiat Res 33: 620-643, 1968.

28. Palma $\mathrm{C}$ and Maggi $\mathrm{CA}$ : The role of tachykinins via NK1 receptors in progression of human gliomas. Life Sci 67: 985-1001, 2000.

29. Friess H, Zhu Z, Liard V, Shi X, Shrikhande SV, Wang L, Lieb K, Kore M, Palma C, Zimmerman A, Reubi JC and Buchler MW: Neurokinin-1 receptor expression and its potential effects on tumor growth in human pancreatic cancer. Lab Invest 83: 731-742, 2003.

30. Nowicki M, Ostalska-Nowicka D and Miskowiak B: In vitro substance P-dependent induction of bone marrow cells in common (CD10) acute lymphoblastic leukaemia. Leuk Res 32: 97-102, 2008

31. Muñoz M, Rosso M, Pérez A, Coveñas R, Rosso R, Zamarriego C, Soult JA and Montero I: Antitumoral action of the neurokinin-1receptor antagonist L-733,060 and mitogenic action of substance $\mathrm{P}$ on human retinoblastoma cell lines. Invest Ophthalmol Vis Sci 46: 2567-2570, 2005.

32. Mori Y, Cai K, Cheng Y, Wang S, Paun B, Hamilton JP, Jin Z, Sato F, Berki AT, Kan T, Ito T, Mantzur C, Abraham JM and Meltzer SJ: A genome-wide search identifies epigenetic silencing of somatostatin, tachykinin-1, and 5 other genes in colon cancer. Gastroenterology 131: 797-808, 2006.

33. Xavier S, Macdonald S, Roth J, Caunt M, Akalu A, Morais D, Buckley MT, Liebes L, Formenti SC and Brooks PC: The vitamin-like dietary supplement para-aminobenzoic acid enhances the antitumor activity of ionizing radiation. Int $\mathrm{J}$ Radiat Oncol Biol Phys 65: 517-527, 2006.

34. Jin GH, Jin SZ, Liu Y, Xu RM, Yang JZ, Pan XN and Liu SZ: Therapeutic effect of gene-therapy in combination with local $\mathrm{X}$-irradiation in a mouse malignant melanoma model. Biochem Biophys Res Commun 330: 975-981, 2005.

35. Zehetmayer M, Kitz K, Menapace R, Ertl A, Heinzl H, Ruhswurm I, Georgopoulos M, Dieckmann K and Pötter R: Local tumor control and morbidity after one to three fractions of stereotactic external beam irradiation for uveal melanoma. Radiother Oncol 55: 135-144, 2000.

36. Höckerfelt U, Franzén L, Norrgård $\mathrm{O}$ and Forsgren S: Early increase and later decrease in VIP and substance P nerve fiber densities following abdominal radiotherapy: a study on the human colon. Int J Radiat Biol 78: 1045-1053, 2002.

37. Salo P, Bray R, Seerattan R, Reno C, McDougall J and Hart DA: Neuropeptides regulate expression of matrix molecule, growth factor and inflammatory mediator mRNA in explants of normal and healing medial collateral ligament. Regul Pept 142: 1-6, 2007.

38. Felderbauer P, Bulut K, Hoeck K, Deters S, Schmidt WE and Hoffmann P: Substance P induces intestinal wound healing via fibroblasts - evidence for a TGF-beta-dependent effect. Int J Colorectal Dis 22: 1475-1480, 2007.

39. Forsgren S, Franzén L, Funegård U, Gustafsson $H$ and Henriksson R: Bilateral irradiation of head and neck induces an enhanced expression of substance $\mathrm{P}$ in the parasympathetic innervation of the submandibular gland. Neuroscience 46: 233-240, 1992.

40. Maynard KI, Stewart-Lee AL, Milner P and Burnstock G: $\mathrm{X}$-irradiation attenuates relaxant responses in the rabbit ear artery. Br J Pharmacol 105: 126-128, 1992. 